\title{
Alterações histológicas dos rins e expressão das metalotioneínas e das proteínas de choque térmico em ratos Wistar após exposição ao fungicida tirame
}

\author{
[Kidney histological alterations and metallothionein and heat shock protein expression in Wistar rats after \\ fungicide thiram exposure] \\ F. Paiva ${ }^{1}$, L. Fialho ${ }^{2}$, A. Rafael ${ }^{3}$, A. Silvério Cabrita ${ }^{3}$, A.M.F. Pereira ${ }^{2}$, F. Capela e Silva ${ }^{2 *}$ \\ ${ }^{1}$ Aluno de pós-graduação - Universidade do Algarve, Portugal \\ ${ }^{2}$ ICAAM - Instituto de Ciências Agrárias e Ambientais Mediterrânicas - Universidade de Évora, Portugal \\ ${ }^{3}$ Instituto de Patologia Experimental - Universidade de Coimbra, Portugal
}

\begin{abstract}
RESUMO
Avaliaram-se as alterações histológicas e a expressão das metalotioneínas (MTs) e das proteínas de choque térmico (Hsp70) nos rins de ratos Wistar após a exposição ao fungicida tirame. Os animais foram distribuídos em três grupos: grupo dieta-padrão; grupo dieta-padrão+óleo de milho; e grupo tirame. Foram encontradas diferenças significativas $(\mathrm{P}<0,05)$ na evolução do peso corporal entre os ratos do grupo tirame e os dos grupos controle e óleo de milho, e não foram verificadas lesões histológicas evidentes nos rins dos animais. Foram encontradas diferenças entre os animais do grupo exposto ao tirame e os dos grupos controle e óleo quanto às características histomorfométricas relativas ao corpúsculo renal - exceto para a proporção área da cápsula de Bowman:área do glomérulo - e relativas aos túbulos contorcidos proximal e distal - exceto para altura do epitélio dos túbulos distais. Nos ratos expostos ao tirame, foi observada imunomarcação positiva para as MTs, de moderada a forte, nos túbulos contorcidos da região cortical, diminuindo do córtex em direção à medula, e forte imunomarcação para as Hsp70 nas áreas do córtex e da medula, no glomérulo e nos túbulos contorcidos. Os resultados sugerem que o tirame pode ter toxicidade crônica nos mamíferos por afetar o seu crescimento e que a expressão das MTs e das Hsp70, provável resposta celular adaptativa ao estresse oxidativo causado pelo tirame, pode ser utilizada como biomarcador de exposição a este químico.
\end{abstract}

Palavras-chave: rato, rins, tirame, histologia, metalotioneínas, proteínas de choque térmico (Hsp70)

\begin{abstract}
The histological alterations and the expression of metallothionein (MTs) and heat shock protein (Hsp70) in the kidney of Wistar rats after thiram fungicide exposure were evaluated. Animals were distributed into three groups: standard diet group, standard diet + corn oil group and thiram group. Significant differences were found $(P<0,05)$ in the evolution of body weight between rats in the thiram group and those in the control and corn oil groups, and no histological lesions were evident in the animals' kidneys. Differences were found among animals in the group exposed to thiram and the control and oil groups regarding histomorphometric characteristics of the renal corpuscle - except for the proportion in the area of Bowman's capsule: glomerulus area - and regarding the height of the epitelium in the distal tubules. In rats exposed to thiram, a positive moderate to strong immunoexpression was observed for MTs, in the cortical convulated tubules decreasing the cortex towards the medulla, and a strong immunoexpression for Hsp70 in the cortex and medulla areas, in the glomerulus and convulated tubules. The results suggest that thiram may have chronic toxicity in mammals affecting their growth, and that the expression of MTs and Hsp70, a probable cellular adaptive response to the oxidative stress caused by thiram, may be used as a biomarker of exposure to this chemical.
\end{abstract}

Keywords: rat, kidney, thiram, histology, metallothioneins, heat shock proteins (Hsp70)

Recebido em 5 de novembro de 2011

Aceito em 23 de março de 2012

*Autor para correspondência (corresponding author)

E-mail: fcs@uevora.pt 


\section{INTRODUÇÃO}

Alguns ditiocarbamatos são amplamente usados como fungicidas agrícolas. O tirame é um dimetilditiocarbamato (TMTD) - dissulfeto de tetrametiltiuram $\left(\mathrm{C}_{6} \mathrm{H}_{12} \mathrm{~N}_{2} \mathrm{~S}_{4}\right)-$ usado em produtos hortícolas, quer em aplicação foliar, quer no tratamento de sementes, como repelente de várias espécies animais. Além disso, é usado como ingrediente de sabões, bronzeadores e sprays antissépticos, como aditivo em óleos lubrificantes e como acelerador de vulcanização de borracha (Mariano et al., 2008). Efeitos tóxicos e tumorigênicos foram observados em diferentes espécies animais expostas ao tirame (Dalvi, 1988; Maita et al., 1991) e inúmeros testes indicam que é genotóxico (Crebelli et al., 1992; Hemavathi e Rahiman, 1996). Embora a Environmental Protection Agency (EPA) e a World Health Organization (WHO) tenham considerado o tirame como ligeiramente tóxico, sua persistência no ambiente não é ainda bem conhecida. Assim, e dadas as inúmeras vias de exposição, este ditiocarbamato pode representar perigo potencial para o homem e outras espécies animais.

As metalotioneínas (MTs) são proteínas não enzimáticas, de baixo peso molecular $(6-7 \mathrm{kDa})$, com elevados níveis de metais $\left(\mathrm{Zn}^{2+}, \mathrm{Cu}^{2+}\right)$ e enxofre (Kagi e Kojima, 1987). As MTs são induzidas em vários sistemas celulares como um importante mecanismo adaptativo em resposta a estímulos ambientais (Klaassen e Liu, 1998). Algumas isoformas das MTs são facilmente induzidas, por metais pesados, hormonas, processos inflamatórios, situações de estresse agudo e muitos químicos (Kagi, 1993). A função protetora das MTs parece basear-se na sua capacidade de se ligar aos íons de metais pesados e como limpador de radicais livres (Kagi, 1993).

As proteínas de choque térmico (Hsp) são um grupo de proteínas classificadas de acordo com o seu peso molecular, as quais podem ser induzidas por choque térmico e outras formas de estresse fisiopatológico (Kiang e Tsokos, 1998). Os mecanismos de funcionamento das Hsp não estão, até essa data, ainda claramente compreendidos, mas os resultados de vários trabalhos sugerem que eles protegem as células estressadas, servindo como chaperones moleculares (Kiang e Tsokos, 1998).
O objetivo deste estudo foi avaliar as alterações histológicas e a expressão das metalotioneínas e das proteínas de choque térmico nos rins de ratos Wistar após a exposição ao fungicida tirame.

\section{MATERIAIS E MÉTODOS}

Vinte e quatro machos Wistar com sete dias de idade foram mantidos em ciclo de luz claro:escuro (12h:12h), a uma temperatura constante de $22^{\circ} \mathrm{C}$, com acesso sem restrições à dieta-padrão e à água. Todos os animais foram submetidos a inspecção e manipulação, para rastreio de patologias, após o que se constituíram três grupos, com oito animais cada, distribuídos aleatoriamente em gaiolas de tipo IV. O primeiro grupo, utilizado como grupo-controle, recebeu dieta-padrão, sem nenhuma manipulação; o segundo grupo, óleo de milho, recebeu a dieta-padrão e $0,1 \mathrm{~mL}$ de óleo de milho, duas vezes por semana; o terceiro, grupo tirame, recebeu a dieta-padrão e o tirame (CAS n. ${ }^{\circ}$ 37-26-8, SIGMA, n. ${ }^{\circ}$ T5638), administrado oralmente, por meio de sonda, na dose de $100 \mathrm{mg}$ $\mathrm{kg}^{-1}$ de peso corporal, suspenso em $0,1 \mathrm{~mL}$ de óleo de milho, duas vezes por semana. Quando da administração, os animais foram pesados individualmente, correspondendo cada peso, em gramas, obtido em balança digital $(0,01 \mathrm{~g})$, à média das duas pesagens semanais. Os animais, sacrificados após 35 dias do início do ensaio por excesso de anestésico, foram mantidos nas condições ambientais e de manutenção determinadas pela legislação em vigor na União Europeia, relativa à experimentação animal (FELASA, http://www.felasa.eu), e em Portugal (Portaria 1005/92). Todos os procedimentos envolvendo os animais foram supervisionados por um investigador reconhecido pela Federation of European Laboratory Animal Science Associations (FELASA).

Após o sacrifício, removeram-se os rins. Depois de serem seccionados sagitalmente, estes foram fixados em formaldeído neutro a $10 \%$, tamponado ( $\mathrm{pH} 7.4$ ), durante 24 horas. Em seguida, procedeu-se ao seu processamento pelas técnicas histológicas de rotina, em sistema automático: inclusão em parafina e corte em micrótomo rotativo, em secções com $5 \mu \mathrm{m}$ de espessura. Os cortes foram estendidos em lâminas de vidro de $75 \times 25 \mathrm{~mm}$ e corados com: hematoxilina e eosina, tricrômico de Masson e reação do ácido periódico-reativo de Schiff 
(PAS), para observação da estrutura geral e eventuais alterações histológicas.

A imuno-histoquímica foi realizada utilizando-se os anticorpos primários contra metalotioneína (NeoMarkers, ref. MS-11.175, Ab-1, clone E9) e Hsp70 (Neomarkers, ref. MS-482, Ab-2, clone W27) pelo método da Streptavidina-biotinaperoxidase (UltraVision Sistema de Detecção de Kit, NeoMarkers, USA, ref ${ }^{\mathrm{a}}$ TP-015-HD), de acordo com as instruções do fabricante. Resumidamente: secções de $5 \mu \mathrm{m}$ de espessura, dos mesmos blocos da análise histológica, foram estendidas em lâminas de vidro de $75 \times 25 \mathrm{~mm}$, tratadas com polilisina, desparafinizadas em xilol e reidratadas em graduações decrescentes de álcool até água destilada. $\mathrm{O}$ bloqueio da peroxidase endógena foi feito pela incubação das lâminas em solução de peróxido de hidrogênio a $3 \%$ em metanol (1 parte de $\mathrm{H}_{2} \mathrm{O}_{2}$ a $30 \%$ para 9 partes de metanol absoluto), por $15 \mathrm{~min}$, em temperatura ambiente, sendo estas posteriormente lavadas em solução salina tamponada com fosfato (PBS, phosphate buffered saline; $\mathrm{pH} 7,4)$, três vezes por $2 \mathrm{~min}$. Antes da incubação anti-Hsp70, os cortes foram pré-tratados para recuperação antigênica, em solução tampão citrato $(\mathrm{pH} 6,0)$, a $98^{\circ} \mathrm{C}$, durante 20min, após o que foram esfriados, durante 20min, em temperatura ambiente, e lavados em PBS, três vezes por $2 \mathrm{~min}$. Os cortes para serem utilizados com o anticorpo anti-MTs não sofreram qualquer pré-tratamento. Para a diminuição das ligações inespecíficas (background), os cortes foram tratados com a solução de bloqueio, durante 5min, em temperatura ambiente, após o que foram incubados, em câmara úmida (overnight, a $4^{\circ} \mathrm{C}$ ), com os respectivos anticorpos primários (antiMT, na diluição de 1:50; anti Hsp70, na diluição de 1:50). Posteriormente, os cortes foram lavados em PBS, três vezes por $2 \mathrm{~min}$, e tratados com anticorpo secundário biotinilado por $15 \mathrm{~min}$, em câmara úmida e temperatura ambiente. Logo após, foram lavados em PBS, três vezes por $2 \mathrm{~min}$, e tratados com o conjugado Streptavidinaperoxidase por mais $15 \mathrm{~min}$ em câmara úmida e temperatura ambiente, sendo lavados novamente em PBS, três vezes por 2 min, e submetidos à revelação com o cromógeno castanho [DAB, Diaminobenzidina] por $5 \mathrm{~min}$. Os cortes foram lavados em água destilada e contracorados com hematoxilina de Mayer por $1 \mathrm{~min}$, posteriormente lavados em água corrente por 1-2min e desidratados em graduações de álcool, clarificados em xilol e montados com Entellan (Merck, nº 107961). Para a interpretação dos resultados, foram incubadas secções adjacentes como controles negativos: (a) sem o anticorpo primário; e (b) com soro normal (concentração semelhante à do anticorpo primário).

As preparações definitivas foram observadas em microscópio fotônico Nikon Eclipse 600, sendo as imagens obtidas por meio de câmara digital Nikon DN100. Para cada animal de cada grupo, foi selecionada uma lâmina, e em cada uma delas observaram-se aleatoriamente: (i) com ampliação de 200X, 40 corpúsculos renais para a medição do perímetro da cápsula de Bowman e do glomérulo, da área do glomérulo, da cápsula de Bowman e do espaço de Bowman; (ii) com uma ampliação de 400X, 30 secções transversais de túbulos contorcidos proximais para a medição da área e do perímetro da secção, da área do lúmen + bordadura em escova, do perímetro do lúmen + bordadura em escova, da área e da altura do epitélio; (iii) com ampliação de 400X, 30 secções transversais de túbulos contorcidos distais para a medição da área e do perímetro da secção, da área do lúmen, do perímetro do lúmen, da área e da altura do epitélio.

Relativamente à expressão das metalotioneínas e das Hsp70, as lâminas foram também examinadas em microscópio fotônico Nikon Eclipse 600, com uma ampliação de 200X, sendo as imagens obtidas por meio de câmera digital Nikon DN100. A intensidade da coloração e a localização de células imunorreativas, nos glomérulos e nos túbulos contorcidos, foram avaliadas em, pelo menos, uma secção do rim por animal, por um observador que desconhecia o grupo a que pertenciam os animais. A imunocoloração foi avaliada de forma qualitativa para o citoplasma e para o núcleo, em separado, de acordo com a seguinte escala: - = negativo; \pm $=$ imunomarcação ocasional, focal; $+=$ imunomarcação fraca; ++ = imunomarcação moderada; $+++=$ imunomarcação intensa.

Os valores obtidos foram analisados estatisticamente utilizando-se o teste não paramétrico de Kruskall-Walls. As diferenças na análise estatística dos dados foram consideradas significativas quando $\mathrm{P}<0,05$. Foi usado $\mathrm{o}$ programa SPSS16. 


\section{RESULTADOS}

$\mathrm{Na}$ evolução do peso corporal (Tab. 1), foram encontradas diferenças significativas $(\mathrm{P}<0,05)$ entre os animais do grupo tirame e os dos outros dois grupos, entre os quais não foram encontradas diferenças significativas.
Não foram encontradas lesões histológicas evidentes nos rins dos animais, e foram observadas diferenças nos rins dos animais dos diferentes grupos relativamente às características histomorfométricas (Tab. 2, 3 e 4).

Tabela 1. Evolução do peso corporal (gramas; média \pm desvio-padrão) de ratos Wistar segundo os tratamentos e a idade $(\mathrm{P})$ de avaliação

\begin{tabular}{lccccc}
\hline Grupo & P0 & P1 & P2 & P3 & P4 \\
\hline Controle & $13,80 \pm 1,43 \mathrm{a}$ & $27,96 \pm 2,07 \mathrm{a}$ & $39,94 \pm 3,43 \mathrm{a}$ & $61,83 \pm 7,01 \mathrm{a}$ & $89,13 \pm 9,07 \mathrm{a}$ \\
Óleo de milho & $12,93 \pm 1,42 \mathrm{a}$ & $26,33 \pm 2,59 \mathrm{a}$ & $38,01 \pm 3,48 \mathrm{a}$ & $56,19 \pm 8,00 \mathrm{a}$ & $84,66 \pm 16,59 \mathrm{a}$ \\
Tirame & $12,90 \pm 1,87 \mathrm{a}$ & $20,98 \pm 3,67 \mathrm{~b}$ & $28,07 \pm 5,11 \mathrm{~b}$ & $37,00 \pm 9,38 \mathrm{~b}$ & $53,92 \pm 17,36 \mathrm{~b}$ \\
\hline
\end{tabular}

P0... P4: $7 \ldots 35$ dias de idade. Valores na mesma coluna, com letras diferentes, diferem entre si (P>0.05).

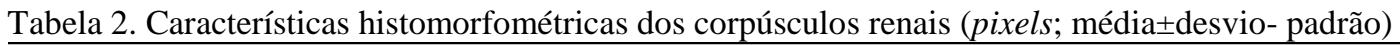

\begin{tabular}{lcccccc}
\hline Grupo & $\begin{array}{c}\text { Área da } \\
\text { cápsula de } \\
\text { Bowman } \\
(\mathrm{AC})\end{array}$ & $\begin{array}{c}\text { Área do } \\
\text { glomérulo } \\
(\mathrm{AG})\end{array}$ & $\begin{array}{c}\text { Ratio } \\
\text { AC/AG }\end{array}$ & $\begin{array}{c}\text { Espaço de } \\
\text { Bowman }\end{array}$ & $\begin{array}{c}\text { Perímetro do } \\
\text { glomérulo }\end{array}$ & $\begin{array}{c}\text { Perímetro da } \\
\text { cápsula de } \\
\text { Bowman }\end{array}$ \\
\hline Controle & $\begin{array}{c}120811,14 \\
\pm\end{array}$ & $\begin{array}{c}104460,49 \\
\pm\end{array}$ & $\begin{array}{c}1,16 \\
\pm\end{array}$ & $\begin{array}{c}16350,66 \\
\pm\end{array}$ & $\begin{array}{c}1242,82 \\
\pm\end{array}$ & $\begin{array}{c}1331,30 \\
\pm\end{array}$ \\
& $13158,77 \mathrm{a}$ & $10361,61 \mathrm{a}$ & $0,036 \mathrm{a}$ & $3729,73 \mathrm{a}$ & $55,78 \mathrm{a}$ & $66,97 \mathrm{a}$ \\
Óleo de milho & 111915,25 & 97133,55 & 1,15 & 14781,71 & 1200,64 & 1276,99 \\
& $\pm 003,57 \mathrm{a}$ & $5955,24 \mathrm{a}$ & $0,036 \mathrm{a}$ & $3008,40 \mathrm{a}$ & $38,04 \mathrm{a}$ & $36,73 \mathrm{a}$ \\
& 87221,62 & 78105,46 & 1,12 & 9116,17 & 1069,78 & 1125,97 \\
Tirame & \pm & \pm & \pm & \pm & \pm & \pm \\
& $8717,99 \mathrm{~b}$ & $7438,17 \mathrm{~b}$ & $0,038 \mathrm{a}$ & $2752,23 \mathrm{~b}$ & $53,70 \mathrm{~b}$ & $59,75 \mathrm{~b}$ \\
\hline
\end{tabular}

Valores na mesma coluna, com letras diferentes, diferem entre si $(\mathrm{P}<0,05)$.

Tabela 3. Características histomorfométricas dos túbulos contorcidos proximais (pixels; média \pm desviopadrão)

\begin{tabular}{|c|c|c|c|c|c|c|}
\hline Grupo & $\begin{array}{l}\text { Área do } \\
\text { túbulo }\end{array}$ & $\begin{array}{l}\text { Perímetro } \\
\text { do túbulo }\end{array}$ & $\begin{array}{c}\text { Área do } \\
\text { lúmen }+ \\
\text { bordadura } \\
\text { em escova }\end{array}$ & $\begin{array}{l}\text { Perímetro do } \\
\text { lúmen }+ \\
\text { bordadura em } \\
\text { escova }\end{array}$ & $\begin{array}{l}\text { Área do } \\
\text { epitélio }\end{array}$ & $\begin{array}{c}\text { Altura do } \\
\text { epitélio }\end{array}$ \\
\hline Controle & $\begin{array}{c}121390,80 \\
\pm \\
17810,41 \mathrm{a}\end{array}$ & $\begin{array}{c}1347,55 \\
\pm \\
91,27 \mathrm{a}\end{array}$ & $\begin{array}{c}36887,63 \\
\pm \\
7434,72 \mathrm{a}\end{array}$ & $\begin{array}{c}765,02 \\
\pm \\
66,00 \mathrm{a}\end{array}$ & $\begin{array}{c}84503,17 \\
\pm \\
11589,20 \mathrm{a}\end{array}$ & $\begin{array}{c}81,60 \\
\pm \\
7,52 \mathrm{a}\end{array}$ \\
\hline Óleo de milho & $\begin{array}{c}113704,69 \\
\pm \\
15544,48 a\end{array}$ & $\begin{array}{c}1303,24 \\
\pm \\
87,93 \mathrm{a}\end{array}$ & $\begin{array}{c}32552,55 \\
\pm \\
8830,00 \mathrm{a}\end{array}$ & $\begin{array}{c}721,05 \\
\pm \\
92,81 \mathrm{a}\end{array}$ & $\begin{array}{c}81152,14 \\
\pm \\
8634,60 \mathrm{a}\end{array}$ & $\begin{array}{c}80,86 \\
\pm \\
4,89 \mathrm{a}\end{array}$ \\
\hline Tirame & $\begin{array}{c}89448,82 \\
\pm \\
14772,63 \mathrm{~b} \\
\end{array}$ & $\begin{array}{c}1171,05 \\
\pm \\
106,78 b\end{array}$ & $\begin{array}{c}23234,51 \\
\pm \\
6431,18 \mathrm{~b} \\
\end{array}$ & $\begin{array}{c}622,60 \\
\pm \\
74,23 \mathrm{~b}\end{array}$ & $\begin{array}{c}66214,31 \\
\pm \\
8977,75 b \\
\end{array}$ & $\begin{array}{c}73,73 \\
\pm \\
5,54 \mathrm{~b} \\
\end{array}$ \\
\hline
\end{tabular}

Valores na mesma coluna, com letras diferentes, diferem entre si $(\mathrm{P}<0,05)$. 
Alterações histológicas...

Tabela 4. Características histomorfométricas dos túbulos contorcidos distais (pixels; média \pm desviopadrão)

\begin{tabular}{|c|c|c|c|c|c|c|}
\hline Grupo & $\begin{array}{l}\text { Área do } \\
\text { túbulo }\end{array}$ & $\begin{array}{l}\text { Perímetro do } \\
\text { túbulo }\end{array}$ & $\begin{array}{l}\text { Área do } \\
\text { lúmen }\end{array}$ & $\begin{array}{l}\text { Perímetro } \\
\text { do lúmen }\end{array}$ & $\begin{array}{l}\text { Área do } \\
\text { epitélio }\end{array}$ & $\begin{array}{c}\text { Altura do } \\
\text { epitélio }\end{array}$ \\
\hline Controle & $\begin{array}{c}74402,72 \\
\pm \\
11532,11 \mathrm{a}\end{array}$ & $\begin{array}{c}1059,81 \\
\pm \\
85,08 \mathrm{a}\end{array}$ & $\begin{array}{c}17029,91 \\
\pm \\
6166,13 a\end{array}$ & $\begin{array}{c}514,44 \\
\pm \\
81,99 a\end{array}$ & $\begin{array}{c}57372,81 \\
\pm \\
7694,78 \mathrm{a}\end{array}$ & $\begin{array}{c}66,13 \\
\pm \\
8,28 \mathrm{a}\end{array}$ \\
\hline Óleo de milho & $\begin{array}{c}73351,99 \\
\pm \\
21724,27 a\end{array}$ & $\begin{array}{c}1050,86 \\
\pm \\
172,33 \mathrm{a}\end{array}$ & $\begin{array}{c}15700,36 \\
\pm \\
4634,26 \mathrm{a}\end{array}$ & $\begin{array}{c}506,23 \\
\pm \\
92,80 \mathrm{a}\end{array}$ & $\begin{array}{c}57651,63 \\
\pm \\
17859,79 \mathrm{a}\end{array}$ & $\begin{array}{c}63,30 \\
\pm \\
9,03 \mathrm{a}\end{array}$ \\
\hline Tirame & $\begin{array}{c}56087,08 \\
\pm \\
10283,07 \mathrm{~b} \\
\end{array}$ & $\begin{array}{c}919,91 \\
\pm \\
86,83 \mathrm{~b} \\
\end{array}$ & $\begin{array}{c}10689,24 \\
\pm \\
2968,92 b\end{array}$ & $\begin{array}{c}412,95 \\
\pm \\
53,38 \mathrm{~b} \\
\end{array}$ & $\begin{array}{c}45397,84 \\
\pm \\
9646,47 \mathrm{~b} \\
\end{array}$ & $\begin{array}{c}59,57 \\
\pm \\
8,64 \mathrm{a} \\
\end{array}$ \\
\hline
\end{tabular}

Valores na mesma coluna, com letras diferentes, diferem entre si $(\mathrm{P}<0,05)$.

Relativamente à área da cápsula de Bowman, foram encontradas diferenças significativas $(\mathrm{P}<0,05)$ entre o grupo tirame e os grupos controle e óleo. Em relação à área do glomérulo, o grupo tirame é também significativamente $(\mathrm{P}<0,05)$ diferente dos grupos óleo e tirame. Não foram observadas diferenças significativas $(\mathrm{P}>0,05)$ entre os grupos no que diz respeito à proporção área da cápsula de Bowman:área do glomérulo. Relativamente ao espaço capsular (espaço de Bowman), os grupos controle e óleo não diferiram entre si, mas apresentaram diferenças significativas $(\mathrm{P}<0,05)$ em relação ao grupo tirame. Finalmente, quanto ao perímetro do glomérulo, foram verificadas diferenças significativas $(\mathrm{P}<0,05)$ entre o grupo tirame e os grupos controle e óleo.

Concernente às diferentes características histomorfométricas analisadas nos túbulos contorcidos, observaram-se diferenças significativas $(\mathrm{P}<0,05)$ em todas elas, entre os animais do grupo tirame e os dos grupos controle e óleo, exceto quanto à altura do epitélio dos túbulos contorcidos distais, para a qual não se observaram diferenças entre os grupos.

No que concerne às metalotioneínas, não houve imunomarcação nos rins dos animais do grupocontrole e nos do grupo óleo de milho, enquanto no grupo tirame foi observada imunomarcação positiva, de moderada a forte, nos túbulos contorcidos da região cortical, diminuindo do córtex em direção à medula (Fig. 1 e Tab. 5). Não foi detectada coloração nos controles negativos.
Quanto às Hsp70, nos animais dos grupos controle e óleo, em geral, pode-se considerar a marcação nula/baixa em ambas as zonas dos rins (córtex e medula), enquanto nos do grupo tirame foi observada forte imunomarcação em ambas as áreas, no glomérulo e nos túbulos contorcidos, mas, em geral, mais forte na zona medular (Fig. 1 e Tab. 5). Não foi detectada coloração nos controles negativos.

\section{DISCUSSÃO}

A diminuição de peso está de acordo com os resultados obtidos em outros trabalhos, nos quais também foi observada redução de peso nos animais em crescimento alimentados com dietas contendo diferentes ditiocarbamatos, designadamente tirame (Dalvi, 1988; Guitart et al., 1996) e zirame (Enomoto et al., 1989).

A toxicidade aguda por ingestão oral de tirame em mamíferos está bem estabelecida. Animais aos quais foi administrado tirame numa única dose, por ingestão oral, e que apresentaram hipertemia, ulceração do trato gastrintestinal, necrose local do fígado e dos túbulos renais (Gosslin et al., 1984, citados por Dalvi, 1988) morreram. Embora se saiba que o tirame causa danos no sistema urinário, a ausência de alterações evidentes pode ser atribuída à dose utilizada, bem como à duração do ensaio. Quanto às características histomorfométricas, os resultados observados sugerem efeito indireto, que se traduziu em decréscimo do crescimento global dos animais, o que é realçado pelo fato de não terem sido encontradas diferenças significativas na proporção área do glomérulo:área da cápsula de Bowman. 


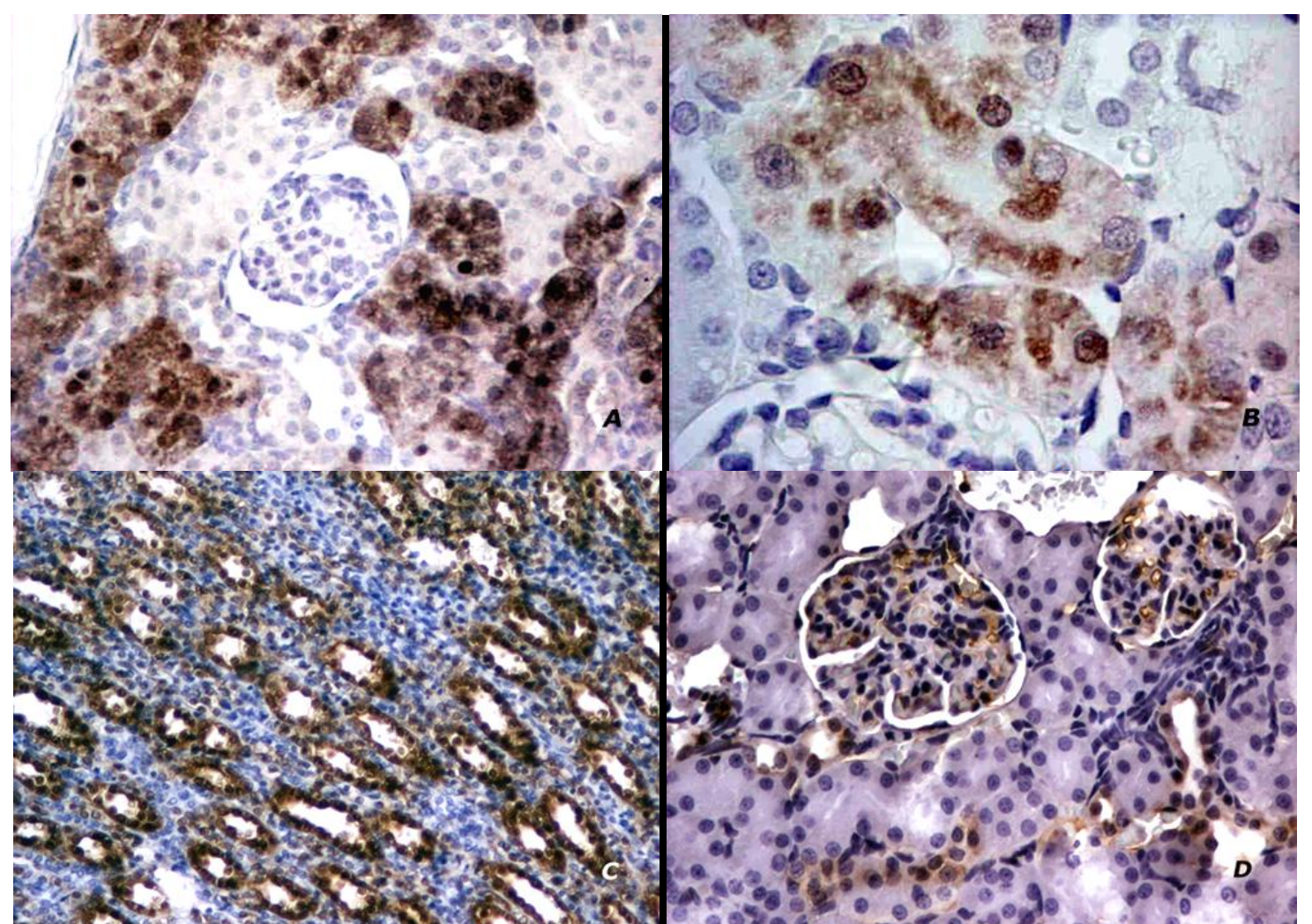

Figura 1. A-B. Expressão das metalotioneínas em ratos do grupo tirame: é possível observar forte marcação, evidenciada pela cor castanha, nos túbulos contorcidos da região cortical, no núcleo e no citoplasma [A, 200x; B, 400x]. C-D. Expressão das Hsp70 nos animais do grupo tirame: é possível observar forte marcação, evidenciada pela cor castanha, no glomérulo e nos túbulos contorcidos da região cortical, no núcleo e no citoplasma [C, 100x; D, 200x]. Contracoloração com hematoxilina de Mayer.

Tabela 5. Expressão imuno-histoquímica das metalotioneínas (MTs) e das Hsp70 ${ }^{1}$

\begin{tabular}{lcccccc}
\hline \multirow{2}{*}{ Grupo } & \multicolumn{2}{c}{ Corpúsculo renal } & \multicolumn{2}{c}{ Túbulo proximal } & \multicolumn{2}{c}{ Túbulo distal } \\
\cline { 2 - 7 } & MTs & Hsp70 & MTs & Hsp70 & MTs & Hsp70 \\
\hline Controle & - & - & - & \pm & - & + \\
Óleo de milho & - & \pm & - & + & - & + \\
Tirame & - & ++ & +++ & ++ & +++ & ++ \\
\hline
\end{tabular}

${ }^{1}-$ = negativo; $\pm=$ imunomarcação ocasional, focal; + = imunomarcação fraca; $++=$ imunomarcação moderada; +++ = imunomarcação intensa.

Têm sido propostos vários mecanismos para explicar os efeitos tóxicos do tirame, incluindo: interrupção na síntese de proteoglicanos, maturação de colágeno e efeitos secundários da atividade da prolil-hidroxilase (Suzuki et al., 2000, 2001), atividade anti-angiogênica (Marikovsky, 2002) e formação de quelatos com o cobre e o zinco, elementos essenciais como cofatores para várias enzimas (Dalvi, 1988). Funcionalmente, as MTs atuam principalmente como reguladoras da homeostase de metais nos tecidos e também como um potente antioxidante que protege as células ou os tecidos dos danos oxidativos. As MTs funcionam como reservatório intracelular de metais, modulando a homeostasia e a transferência de elementos essenciais $(\mathrm{Zn}$ e $\mathrm{Cu})$, de modo a controlar a sua biodisponibilidade intracelular para metaloenzimas, pigmentos respiratórios, etc. (Kagi, 1993). Por outro lado, são um potente antioxidante contra ampla gama de radicais livres, incluindo os radicais mais ativos. $\mathrm{O}$ aumento da expressão das MTs nos animais expostos à ação do tirame pode estar associado a alterações na homeostasia dos metais na célula (Aschner, 1996) - em que uma eventual indisponibilidade, 
em resultado da formação de quelatos, seria compensada com a transferência a partir das metalotioneínas -, ou pode traduzir uma resposta adaptativa ao aumento do estresse oxidante causado pelo tirame (Cereser et al., 2001).

Os estímulos que induzem à síntese de Hsp e a respostas de estresse são numerosos e variados, incluindo: poluentes ambientais (como metais pesados e pesticidas organofosforados), condições patofisiológicas (designadamente estresse oxidativo, estresse mecânico, processos inflamatórios, infecções e processos fisiológicos particulares) e condições normais (designadamente durante o desenvolvimento embrionário, a diferenciação, o ciclo celular e a estimulação hormonal) (Kiang e Tsokos, 1998). As Hsp protegem proteínas e ácidos nucleicos dos danos causados pelo estresse oxidativo, evitando apoptose, supressão de citocinas próinflamatórias e reparação de canais de íons (Beckman et al., 1990). A maior parte das Hsp são constitutivas, ou seja, estão sempre presentes nas células normais em níveis baixos, e todas elas desempenham um papel-chave no metabolismo celular (Beckman et al., 1990), o que explica alguma imunomarcação nos animais dos grupos não expostos à ação do tirame. A expressão aumentada nas Hsp70 dos animais expostos à ação do tirame sugere, tal como para as MTs, uma resposta celular adaptativa ao estresse oxidante causado pelo tirame (Cereser et al., 2001).

Em conclusão, os resultados sugerem que o tirame pode ter toxicidade crônica nos mamíferos, afetando o seu crescimento. Sugerem, também, que a expressão das MTs e das Hsp70, provável resposta celular adaptativa ao estresse oxidante causado pelo tirame, pode ser utilizada como biomarcador de exposição a este químico.

\section{AGRADECIMENTOS}

Este trabalho é financiado por Fundos FEDER através do Programa Operacional Factores de Competitividade - COMPETE e por Fundos Nacionais através da FCT - Fundação para a Ciência e a Tecnologia no âmbito do Projecto Estratégico PEst-C/AGR/UI0115/2011.

\section{REFERÊNCIAS}

ASCHNER, M. The functional significance of brain metallothioneins. FASEB J., v.10, p.11291136, 1996.

BECKMANN, R.P.; MIZZEN, L.A.; WELCH, W.J. Interaction of Hsp70 with newly synthesized proteins: implications for protein folding and assembly. Science, v.248, p.850-854, 1990.

CERESER, C.; BOGET, S.; PARVAZ, P. et al. Thiram-induced cytotoxicity is accompanied by a rapid and drastic oxidation of reduced glutathione with consecutive lipid peroxidation and cell death. Toxicology, v.163, p.153-162, 2001.

CREBELLI, R.; ZIJNO, A.; CONTI, L. et al. Further in vitro and in vivo mutagenicity assays with thiram and ziram fungicides: bacterial reversion assays and mouse micronucleus test. Teratog. Carcinog. Mutagen, v.12, p.97-112, 1992.

DALVI, R.R. Toxicology of thiram (tetramethylthiuram disulfide): A review. Vet. Hum. Toxicol., v.30, p.480-482, 1988.

ENOMOTO, A.; HARADA, T.; MAITA, K. et $a l$. Epiphyseal lesions of the femur and tibia in rats following oral chronic administration of zinc dimethyldithiocarbamate (ziram). Toxicology, v.54, p.45-58, 1989.

GUITART, R.; MATEO, R.; GUTIERREZ, J.M. An outbreak of thiram poisoning on spanish poultry farms. Vet. Human Toxicol., v.38, p.287-288, 1996.

HEMAVATHI, E.; RAHIMAN, M.A. Effect of ziram, thiram, and dithane M-45 on bone marrow cells of mice-assessed by micronucleus test. Bull. Environ. Contam. Toxicol., v.56, p.190-196, 1996.

KAGI, J.H. Evolution, structure and chemical activity of Class I metallothioneins: an overview, In: SUZUKI, K.T.; IMURA, N.; KIMURA, M. (Eds.). Metallothionein III: Biological Roles and Medical Implications. Berlin:Verlag, 1993. p.29-56. 
KAGI， J.H.; KOJIMA, Y. Chemistry and biochemistry of metallothionein. Experientia Suppl., v.52, p.25-61, 1987.

KIANG, J.G.; TSOKOS, G.C. Heat shock protein $70 \mathrm{kDa}$ : molecular biology, biochemistry, and physiology. Pharmacol. Ther., v.80, p.183201, 1998.

KLAASSEN， C.D.; LIU， J. Induction of metallothionein as an adaptive mechanism affecting the magnitude and progression of toxicological injury. Environ. Health Perspect., v.106, p.297-300, 1998

MAITA, K.; TSUDA, S.; SHIRASU, Y. Chronic toxicity studies with thiram in Wistar rats and beagle dogs. Fundam. Appl. Toxicol., v.16, p.667-686, 1991.

MARIANO, R.M.; VISCONTE, L.L.; OLIVEIRA, M.R. et al. Avaliação de bis(4-metilfenilditiocarbimato) zincato (II) de tetrabutilamônio como acelerador em composições de borracha natural. Polímeros: Cienc. Tecnol., v.18, p.297-301, 2008.
MARIKOVSKY, M. Thiram inhibits angiogenesis and slows the development of experimental tumours in mice. Br. J. Cancer, v.86, p.779-787, 2002.

SUZUKI, T.; SRIVASTAVA, A.S.; KUROKAWA, T. Experimental induction of jaw, gill and pectoral fin malformations in Japanese flounder, Paralichthys olivaceus, larvae. Aquaculture, v.185, p.175-187, 2000.

SUZUKI, T.; KUROKAWA, T.; SRIVASTAVA, A.S. Induction of bent cartilaginous skeletons and undulating notochord in flounder embryos by disulfiram and a,a'-dipyridyl. Zoolog. Sci., v.18, p.345-351, 2001. 